\title{
COMPORTAMENTO DA MUSCULATURA DAS ARTERÍOLAS INTRA-HEPÁTICAS NA FORMA HEPATESPLÊNICA DA ESQUISTOSSOMOSE MANSÔNICA
}

\section{Maria do Socorro Almeida Barbosa* Edmundo Chapadeiro e Alberto Nicolau Raick}

\begin{abstract}
A determinação da relação parede-lume das arteriolas intra-hepáticas, na esquistossomose mansônica (forma hepatesplênica), demonstra a existência de uma hipotrofia da camada muscular daqueles vasos. Esse achado sugere redução do fluxo sangüineo arterial hepático nessa entidade.
\end{abstract}

Palavras chaves: Esquistossomose. Esquistossomose hepatesplênica. Lesões arteriolares. Hipertrofia arteriolar.

A natureza e o significado das lesões arteriais intra-hepáticas, que ocorrem em portadores da forma hepatesplênica da esquistossomose mansônica, são controvertidos. Segundo alguns, o sistema arterial é pouco acometido 4591112 ; segundo outros, o sistema mostra-se hipertrófico 12381014 com aumento do fluxo sangüineo; um terceiro ponto de vista admite ${ }^{9}$ que a referida rede apresenta-se atrófica em conseqüência da redução do fluxo arterial.

Até o presente, entretanto, faltam pesquisas morfometricas da musculatura dos ramos arteriais intra-hepáticos, especialmente das arteriolas no sentido de determinar o comportamento daquela camada e sua relação com as modificações hemodinâmicas no sistema. A finalidade deste trabalho é estudar esse comportamento das arteriolas, através da relação parede-lume, em portadores de fibrose hepática esquistossomótica.

\section{MATERIAL E MÉTODOS}

O material de estudo consta de fragmentos de fígado, de cinco portadores da forma hepatesplênica da esquistossomose mansônica, não acompanhados de doença hipertensiva sistêmica, necropsiados no Laboratório de Patologia da Faculdade de Ciências da Saúde da Universidade de Brasilia. Como controle, foram utilizados fragmentos de fígado de cinco indivíduos falecidos acidentalmente e necropsiados no Departamento de Patologia, Medicina Legal e Deontologia Médica da Faculdade de Medicina do Triângulo Mineiro (Uberaba) sem qualquer hepatopatia e nos

Laboratório de Patologia da Faculdade de Ciências da Saúde, Departamento de Medicina Complementar, Universidade de Brasilia, Brasília, DF e da Faculdade de Medicina do Triângulo Mineiro, Uberaba, MG.

* Bolsista do CNPq (Bolsa de Iniciação Científica) - Processo no $101452 / 84$.

Recebido para bublicação em 31/8/87 quais pôde-se afastar também doença hipertensiva arterial sistêmica (Tabela 1).

Cortes em parafina de 5 a $7 \mu \mathrm{m}$ do figado, corados pela hematoxilina-eosina, foram utilizados para determinação da relação parede-lume. Em 20 arteriolas, tomadas de cada caso, localizadas nos espaços porto-biliares e nas quais o processo inflamatório periportal não produzia qualquer tipo de deformidade, foi determinada a média das relaçōes parede-lume segundo Kernohan, Anderson e Keith ${ }^{6}$. Considerou-se arteriola como a menor artéria desprovida de uma camada conjuntiva subendotelial; esses vasos estão compreendidos entre 40 e $120 \mu \mathrm{m}$ de diâmetro.

$O$ teste $t$ de Student foi aplicado entre as médias das relações parede-lume das arteríolas de ambos os grupos.

\section{RESULTADOS}

A Tabela 2 mostra que a média das relações parede-lume das arteriolas hepáticas na fibrose esquis-

Tabela 1 - Distribuição do material segundo o sexo e a idade

\begin{tabular}{lccccc}
\hline & Protocolo & & Sexo & Idade \\
\cline { 1 - 2 } Fibrose & A & $76-081$ & & M & 26 \\
Hepática & A & $77-091$ & & M & 48 \\
Esquistossomótica & A & $78-025$ & & M & 20 \\
& A & $78-121$ & & F & 23 \\
& A & $78-122$ & & F & 14 \\
& & & & & \\
Controles & A & $79-84$ & & M & 22 \\
& A & $80-84$ & & M & 18 \\
& A & $88-84$ & & M & 24 \\
& A & $89-84$ & & M & 23 \\
& A & $64-85$ & & M & 35 \\
\hline
\end{tabular}


Barbosa MSA, Chapadeiro E, Raick AN. Comportamento da musculatura das artertolas na forma hepatesplênica de esquistossomose mansónica. Revista da Sociedade Brasileira de Medicina Tropical 21: 21-22, Jan-Mar, 1988

Tabela 2 - Relação parede-lume das arteriolas intrahepáticas

\begin{tabular}{lcc}
\hline & $\begin{array}{c}\text { Fibrose } \\
\text { Esquistossomótica }\end{array}$ & Controle \\
\hline N. de casos & 5 & 5 \\
Média aritmética da relação & & \\
parede-lume & 0,60 & 0,73 \\
Desvio padrão & 0,09 & 0,10 \\
Coeficiente de variaçāo & $15 \%$ & $14 \%$ \\
\hline
\end{tabular}

tossomótica é menor que aquela dos controles. Esta diferença é estatisticamente significativa $(t=2,29$; $0,025<\mathrm{P}>0,05$ ).

\section{COMENTÁRIOS}

Embora na fibrose hepática esquistossomótica as arteriolas intra-hepáticas possam apresentar-se espessadas 134579 , esse espessamento não parece resul$\operatorname{tar}$ da hipertrofía verdadeira (aumento volumétrico das fibras musculares lisas) da camada média daqueles vasos. Nas arteriolas estudadas e onde faltava qualquer proliferação intimal, a camada muscular mostrava-se atrófica quando comparada com aquela dos vasos-controles. Essa atrofia nos leva a admitir a existência de um fluxo arterial intra-hepático reduzido, o que estaria de acordo com as observaçōes de Mies e cols $^{9} \mathrm{em}$ arteriografias seletivas do figado com fibrose de Symmers, contrariamente às opiniões de alguns autores 13812 .

\section{SUMMARY}

The determination of the wall-to-lumen ratio of hepatic arterioles in hepatosplenic schistosomiasis shows atrophy of the muscular layer of those vessels. This finding suggests a reduction of hepatic arterial flow as reported by others.

Key words: Schistosomiasis. Hepatosplenic schistosomiasis. Arteriolar lesions. Arteriolar hypertrophy

\section{REFERÊNCIAS BIBLIOGRÁFICAS}

1. Andrade ZA, Andrade SG. Patologia da esquistossomose hepato-esplênica In: Aspectos peculiares da infec- çāo por Schistossoma mansoni. Centro Editorial e Didático da UFBA, Salvador, 1984.

2. Andrade ZA, Bina JC. A patologia da forma hepatesplènica na esquistossomose mansônica em sua forma avançada (Estudo de 232 necrópsias completas). Memórias do Instituto Oswaldo Cruz 78:285-305, 1983.

3. Andrade ZA, Cheever AW. Alterations of intrahepatic vasculature in hepatosplenic schistosomiasis mansoni. The American Journal of Tropical Medicine and Hygiene 20: 425-432, 1971

4. Bogliolo L. Segunda contribuição ao conhecimento do quadro anatômico do figado na esquistossomose mansônica hepato-esplènica. O Hospital 45:507-542, 1955.

5. Bogliolo L. Subsídios para o conhecimento da forma hepato-esplênica e da forma toxêmica da esquistossomose mansônica. Serviço Nacional de Educação Sanitária, Ministério da Saúde, Rio de Janeiro, 1958.

6. Kernohan J, Anderson EW, Keith NM. The arterioles in cases of hypertension. Archives of Internal Medicine 44:395-423, 1929.

7. Lichtemberg $F$. Lesions of the intrahepatic portal radicles in Manson's schistosomiasis. The American Journal of Pathology 31:757-771, 1955.

8. Magalhães Filho A, Menezes H, Barros Coelho R. Patogênese da fibrose hepática na esquistossomose mansoni (estudo das alterações vasculares portais mediante modelo plástico). Revista da Associação Médica Brasileiras6:284-294, 1960

9. Mies S, Larsson E, Mori T, Rosa P, Raia S. O sistema porta e as artérias hepática, esplênica e mesentérica superior na esquistossomone hepatesplênica. Estudo angiográfico. Revista do Hospital das Clínicas da Faculdade de Medicina de São Paulo 35:121-131, 1980.

10. Raso P. Lesões vasculares intra-hepaticas na forma hepato-esplênica da esquistossomose mansônica. Hospital 52:63-100, 1957.

11. Ribeiro Jorge PA, Carvalhal SS. Sobre a rede vascular intra-hepática na esquistossomose mansônica, forma de Symmers. Estudo com modelos plásticos. Revista da Associação Médica Brasileira 13:435-441, 1967.

12. Ribeiro Jorge PA, Zancaner W, Guimarães RF, CarvaIhal SS. $O$ gradiente de oxigênio e o fluxo sanguíneo hepático na esquistossomose mansônica hepatosplênica, forma de Symmers. Revista da Associação Médica Brasileira 13:442-445, 1967.

13. Speranzini MB. Vascularização arterial do fígado na fibrose hepática esquistossomótica após anastomose espleno-renal (Estudo Angiográfico). Tese de Docência, Universidade de São Paulo, São Paulo, 1971.

14. Warren KS. Hepatosplenic schistosomiasic a great neglected disease of the liver. GUT 19:572-577, 1978. 